Archived version from NCDOCKS Institutional Repository http://libres.uncg.edu/ir/asu/

\title{
Appalachỉan
}

B O O N E, N O R T H C A R O L I N A

\section{Dietary effects on nontraditional risk factors for heart disease}

\author{
Authors: Martin Root, John J.B. Anderson
}

\begin{abstract}
Diet has long been known to play a key role in modifying the major risk factors for heart disease, namely, dyslipidemia and hypertension. Numerous recent advances have suggested that dietary components, particularly those in a traditional Mediterranean diet, may also improve nontraditional risk factors. Fish and fish n-3 fatty acids reduce the risk of cardiac arrhythmias. The monounsaturated fatty acids in olive oil may inhibit and reverse the clotting process. The phytochemicals in fruits and vegetables may reduce both inflammation and clotting. Alcohol, usually in the form of red wine, may lower inflammation and improves endothelial function. The traditional Mediterranean diet is low in processed foods containing trans fatty acids and high glycemic index ingredients which increase inflammation and raise lipoprotein (a). The combined effects of these foods has been shown to reduce significantly the risk of heart disease.
\end{abstract}

Martin Root, John J.B. Anderson(2004)Dietary effects on nontraditional risk factors for heart disease. Nutrition Research [doi:10.1016] (ISSN 0271-5317) 


\title{
Dietary effects on nontraditional risk factors for heart disease \\ Martin Root, John J.B. Anderson
}

\begin{abstract}
Diet has long been known to play a key role in modifying the major risk factors for heart disease, namely, dyslipidemia and hypertension. Numerous recent advances have suggested that dietary components, particularly those in a traditional Mediterranean diet, may also improve nontraditional risk factors. Fish and fish n-3 fatty acids reduce the risk of cardiac arrhythmias. The monounsaturated fatty acids in olive oil may inhibit and reverse the clotting process. The phytochemicals in fruits and vegetables may reduce both inflammation and clotting. Alcohol, usually in the form of red wine, may lower inflammation and improves endothelial function. The traditional Mediterranean diet is low in processed foods containing trans fatty acids and high glycemic index ingredients which increase inflammation and raise lipoprotein (a). The combined effects of these foods has been shown to reduce significantly the risk of heart disease.
\end{abstract}

Keywords: Coronary heart disease; Mediterranean diet; Hemostasis; Arrhythmia; Inflammation; Endothelial function

\section{Introduction}

The major risk factors of coronary heart disease (CHD), known for many decades, include dyslipidemia, hypertension, smoking, and diabetes. Drugs that reduce LDL cholesterol or lower blood pressure help reduce the burden of this disease. More recently, additional risk factors have been elucidated that suggest new pathologic mechanisms at work in the causation of CHD.

Dietary intervention has always been an important instrument for ameliorating heart disease. The American Heart Association has developed recommended interventional diets. Beginning the 1960s new dietary information has affected food consumption patterns in economically developed countries and may be responsible, in part, for the reduction in CHD. However, as the Study showed, large differences exist between the CHD incidence rates among countries that are not explained by the major risk factors [1].

\section{Diet and CHD in Mediterranean countries}

The countries along the Mediterranean coast (in particular Spain, southern France, Italy, and Greece) have lower rates of CHD than would be expected from the average major risk factors found in those countries. The diets in these areas have been credited by many for these effects (Table 1). Of course, considerable variety exists in the diets of these countries; however, compared to the average diet in the United States (Table 1) several common factors have attracted attention (Table 2). Olive oil consumption is particularly high across this region. Limited red meat and moderate fish consumption is common. Fruit and vegetable consumption is high. Moderate alcohol intake, especially wine with meals, is common. 
Staples include legumes, rice, and pasta. Dairy products are available but are not consumed in large amounts.

The Lyon Diet Heart Study used a slightly modified Mediterranean diet for the treatment of 302 patients with CHD. This diet reduced subsequent heart attacks by $72 \%$ over 3.8 years [2]. In addition, the Gruppo Italiano per lo Studio della Sopravvivenza nell' Infarto Miocardico

\section{Table 1}

Comparison of typical northern European and North American diet with common elements of a traditional Mediterranean diet

\begin{tabular}{|c|c|c|}
\hline Dietary elements & European-American diet & Traditional Mediterranean diet \\
\hline Fats & Saturated and $n-6$ fatty acid-rich vegetable oils & Olive oil \\
\hline Meat & High in red meat, also poultry, low fish & $\begin{array}{l}\text { Low in red meat and more poultry, } \\
\text { moderate (and variable) fish }\end{array}$ \\
\hline Legumes and nuts & Some peanuts, low in nuts and dried beans & Beans, nuts, seeds \\
\hline Grains & Refined flour in breads, many sweets & $\begin{array}{l}\text { More pasta and bread, and less } \\
\text { sweets }\end{array}$ \\
\hline Fruits and vegetables & Low to moderate consumption & $\begin{array}{l}\text { Moderate to high consumption of } \\
\text { green vegetables, roots, and fresh } \\
\text { fruit }\end{array}$ \\
\hline Dietary fiber & Low & Moderate to high \\
\hline Alcohol & Low and variable & Wine with meals \\
\hline Processed foods & High, including baked products and snacks & $\begin{array}{l}\text { Low, with fresh fruits and vegetables, } \\
\text { whole grains and legumes }\end{array}$ \\
\hline Dairy foods & Milk, cheese, ice cream & $\begin{array}{l}\text { Less milk and ice cream, moderate } \\
\text { cheese }\end{array}$ \\
\hline
\end{tabular}


Table 2

Summary of the effects of a Mediterranean diet and additional factors on non-traditional risk factors of heart disease

\begin{tabular}{|c|c|c|c|}
\hline Feature of diet & $\begin{array}{l}\text { More or less in } \\
\text { Mediterranean diet }\end{array}$ & Active component & Risk factor effects \\
\hline \multicolumn{4}{|l|}{ Beneficial factors } \\
\hline Fish & More & $\begin{array}{l}\text { Long chain } n-3 \\
\text { polyunsaturated } \\
\text { fatty acids }\end{array}$ & $\begin{array}{l}\text { Jeardiac arrhythmia } \\
\text { Jplatelet aggregation } \\
\text { 仓FMV } \\
\text { Zlipoprotein (a) } \\
\text { Uinflammation }\end{array}$ \\
\hline Olive oil and nuts & More & $\begin{array}{l}\text { Monounsaturated } \\
\text { fatty acids }\end{array}$ & $\begin{array}{l}\text { L platelet aggregation } \\
\text { Jfibrinolysis } \\
\text { 介FMV }\end{array}$ \\
\hline Fruit and vegetables and garlic & More & $\begin{array}{l}\text { Phytochemical, } \\
\text { vitamins, and } \\
\text { fiber }\end{array}$ & $\begin{array}{l}\text { 仓 Platelet } \\
\text { aggregation } \\
\text { fibrinolysis } \\
\text { antioxidants } \\
\text { CRP 』 } \\
\text { Fibrinogen } \\
\text { Homocysteine } \\
\text { FMV }\end{array}$ \\
\hline Red wine & More & Alcohol & 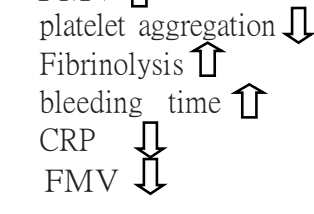 \\
\hline \multicolumn{4}{|l|}{ Adverse factors } \\
\hline Processed foods and snacks & Less & $\begin{array}{l}\text { Trans and } \\
\text { saturated } \\
\text { fatty acids, } \\
\text { high - glycemic } \\
\text { index foods }\end{array}$ & 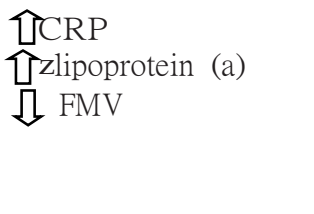 \\
\hline \multicolumn{4}{|l|}{ Other factors } \\
\hline Obesity & & & $\begin{array}{l}\text { 介 CRP } \\
\text { 『MV }\end{array}$ \\
\hline Exercise & & & $\begin{array}{l}\text { I CRP } \\
\text { 仓 FMV }\end{array}$ \\
\hline Antioxidant vitamin supplements & & & no effect \\
\hline B-vitamin supplements & & $\begin{array}{l}\text { folate, vitamins } \mathrm{B}_{6} \\
\text { and } \mathrm{B}_{12}\end{array}$ & A homocysteine \\
\hline
\end{tabular}

$\mathrm{CRP}=\mathrm{C}$-reactive protein; FMV = flow-mediated vasodilation.

(GISSI-Prevenzione) trial gave general dietary advice toward a Mediterranean-style diet to 11,323 CHD patients. Researchers found that the quartile of subjects who most closely followed the dietary advice had a $49 \%$ reduction in the odds of subsequent death [3]. These and similar studies emphasize an entire food pattern, as opposed to one or another specific nutrient, that is effective in reducing the risk of CHD. 


\section{Mechanism of action of components of the Mediterranean diet}

The Lyon and GISSI studies are most interesting in that little or no effect of the diets was observed on the traditional risk factors of blood pressure and serum lipids. Therefore, the effects of these dietary components must be acting through other pathological pathways involved in CHD. These other components of diet and their mechanisms are the subject of this review. Possible mechanisms involved in CHD include the clotting process, the systemic inflammatory response, cardiac arrhythmias, and endothelial function. Dietary components that affect these pathways include fish and the n-3 fatty acids, olive oil and the monounsaturated fatty acids (MUFA), the lack of trans fatty acids, various phytochemicals and antioxidants, and moderate alcohol consumption.

Each of the above mechanisms is complex, consisting of a unique set of pathways, cascades, inhibitors, biomarkers, and local and systemic effects and interactions. Since CHD is largely a vascular disease and blood is a readily available material, numerous biomarkers of various pathways have been postulated. However, only a few have been shown to be significantly predictive of cardiac events in clinical and epidemiological studies. These other mechanisms have also been studied in biological systems not directly connected to their vascular effects in humans. Information about the complex pathways has been established in cell culture and animal studies, and with ex vivo and in vitro measurements. Although nutrient effects may be measured in these systems, the relevance to the chronic human condition of atherosclerotic CHD is often a leap of faith. This review also assesses the relevance of these findings in the light of observed dietary effects on CHD.

\section{Inflammation}

Ross and Glomset in 1973 first identified inflammation as a cause of atherosclerosis [4]. Although much is known about the process of inflammation, only a few biomarkers have been correlated directly with CHD. C-reactive protein (CRP) has gained considerable currency as a new risk factor for heart disease in the last few years [5] and has led to a renewed interest in the role of systemic inflammation in heart disease.

Many of the phytochemicals in fruits and vegetables have strong antioxidant properties that have been implicated through their effects on cell and animal model systems. However, when the major nutrient antioxidants, a-tocopherol, vitamin $\mathrm{C}$, and $h$-carotene, have been tested in purified forms in clinical trials, they have been found to be ineffective in preventing actual coronary events [6]. Thus, the direct actions of pro-oxidants and free radicals on the atherosclerotic process have been cast in some doubt. These putative direct actions, as measured in model systems, include the oxidation of LDL and the production of malondialdehyde-derived products.

Pro-oxidants may have more powerful biological effects indirectly through the inflammatory process [7]. Nuclear factor $-n \mathrm{~B}(\mathrm{NF} n \mathrm{~B})$ is a critical messenger in initiating inflammation. Reactive oxygen species play a key role in releasing cytoplasmic NFjB for translocation to the nucleus and activation of the transcription of genes for numerous cytokines, growth factors, and adhesion molecules. Dietary antioxidants may have a limited role in reducing inflammation through reduction of reactive oxygen species and the 
inactivation of NF $n \mathrm{~B}$. For example, g-tocopherol has also been shown to decrease the release and activation of NF $n \mathrm{~B}[8]$.

The n-3 fatty acids, a-linolenic acid, eicosapentaenoic acid, and docosahexaenoic acid, being highly unsaturated, have mixed effects of the oxidant/antioxidant pathways and markers. However, they have been shown to affect a fairly consistent suppression of the inflammatory response. It has been hypothesized that this suppression is through the production of $n-3$ derived eicosanoids, that displace eicosanoids derived from the $n-6$ fatty acid arachidonic acid, the primary substrate of eicosanoid synthesis [9]. There is a reduction in the more inflammatory $n-6$ derived leukotriene B4 and an increase in $n-3$ derived leukotriene B5, a weaker inducer of inflammation. Supplementation with n-3 fatty acids has also been shown to reduce the expression of pro-inflammatory cytokine IL-1 [10]. Intake of trans fatty acids has been positively associated with systemic inflammatory markers in healthy women [11].

The acute phase response, as exemplified by the rise in serum CRP, has come under renewed interest since the mid 1990s when, using a newer high sensitivity assay, it was discovered that small increases in baseline CRP indicate increased risk for CHD [12]. CRP levels are positively correlated with many of the known risk factors for heart disease, including smoking, obesity, lack of exercise, diabetes, and use of postmenopausal hormone replacement therapy. The synthesis of CRP is under the regulatory control of IL-6. Although clinical and epidemiological studies are quite clear about the role of CRP as a predictive risk factor, the mechanism of action is still not elucidated. What is clear is that regimens such as dieting and exercise that have only modest effects on the known major risk factors, i.e., hypertension and dyslipidemia, have major effects on CRP.

Inflammation may also, in part, explain the alcohol effect. Modest alcohol consumption, in the range of $1-2$ drinks per day, lowers heart disease risk compared to complete abstinence. Alcohol consumption in the same range also lowers CRP [13]. Consuming lower glycemic index foods (foods digested or absorbed more slowly and that cause less of a rise in blood glucose and insulin) also lowers CRP [14]. Exercise is inversely associated with CRP [15] and weight loss reduces CRP [16]. A diet high in plant sterols, soy protein, viscous soluble fiber, and almonds has recently been shown to lower CRP by $28 \%$ [17].

\section{Cardiac arrhythmias}

One of the most well established dietary effects in preventive cardiology is that of the protective effects of fish and fish oils on cardiac sudden death. The GISSI study found a decrease in sudden death $(R R=0.47)$ in the $n-3$ fatty acid-intervention group [18]. Several large prospective cohort studies have found similar results [19-21]. The findings from the Physicians Health Study are particularly dramatic with a $90 \%$ reduction in sudden death risk among those in the highest quartile of blood levels of long-chain n-3 fatty acid (Fig. 1) [19]. Although the n-3 fatty acids have numerous effects on pathways leading to atheromas and thrombosis, the largest impact may be on the heart itself [22]. In animal models of reperfusion, n-3 fatty acids reduce the severity of reperfusion-induced arrhythmia [23]. Purified long-chain n-3 fatty acids reduced fatal ventricular fibrillation in ischemic dogs [24]. These substances specifically inhibit the fast, voltage-dependent sodium entry current in 


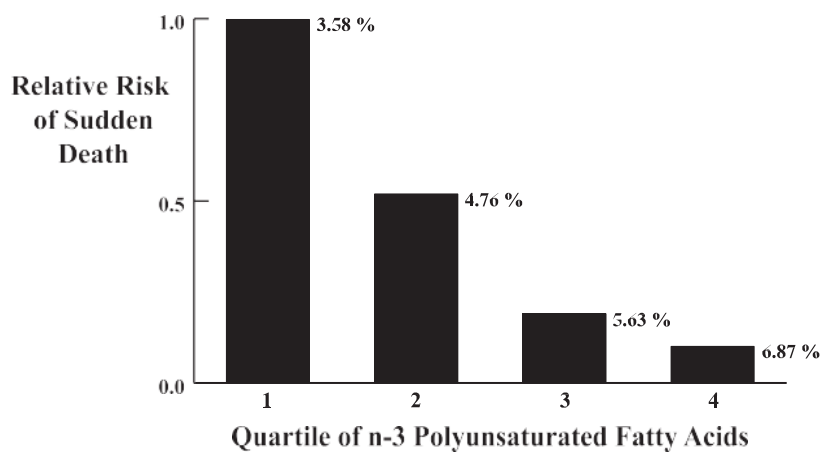

Fig. 1. Relative risk of sudden death across quartiles of blood levels of long-chain n-3 fatty acids from the Physicians Health Study [16]. Numbers by bars are average percentages of n-3 fatty acids in blood of subjects.

cardiac myocytes $[25,26]$. In human subjects, animal model, and cell culture experiments, these effects are observed at rather low concentrations, approximating those seen in people who consume moderate amounts of fatty fish [22].

\section{Hemostasis}

Hemostasis is a complex mechanism with interacting activating cascades of biochemical factors. In a manner similar to the inflammatory process, hemostasis is a largely vascular process with numerous circulating agents. These can easily be measured in a peripheral blood sample but the correlation between these numerous biomarkers and CHD events is limited. Increased fibrinogen has been known for a long time as a cardiovascular risk factor [27]. Other newer hemostatic risk factors may include factor VIII, von Willebrand factor, fibrin Ddimer, and tissue plasminogen activator [28-30]. Three major pathways exist for the forming and dissolving of clots (Fig. 2). The coagulation cascade involves numerous protein factors and results in the conversion of fibrinogen to fibrin. The platelet activation pathway initiates the aggregation of platelets and their inclusion in the growing thrombus. The counterbalancing fibrinolytic pathway breaks down fibrin and slows nascent thrombus formation.

Numerous dietary components have been shown to act on this complex system. The n-3 fatty acids have been studied extensively and in model systems (usually at high doses) have a notable effect reducing platelet aggregation. Garlic, an important part of the Mediterranean diet, reduces platelet aggregation, increases fibrinolytic activity, and reduces fibrinogen concentration and resulting plasma viscosity [31,32]. Alcohol probably has its major effect on CHD through increasing HDL, but in human studies alcohol also reduces factor VIII and platelet aggregation and increases tissue plasminogen activator and bleeding time [33-36]. An intriguing recent study showed that modest beer consumption altered the secondary structure of fibrinogen, reducing its stability and its potential contribution to CHD risk [37]. Most hemostatic effects of alcoholic beverages do not seem to be beverage-specific. Although stearic acid, unlike other saturated fatty acids, has been shown to have little effect on cholesterol level, it has recently been shown to increase fibrinogen levels [38].

Lipoprotein (a) (LPA) is a known CHD risk factor. Although it is a variant of atherogenic LDL, probably its more important role in plaque formation is due to its 


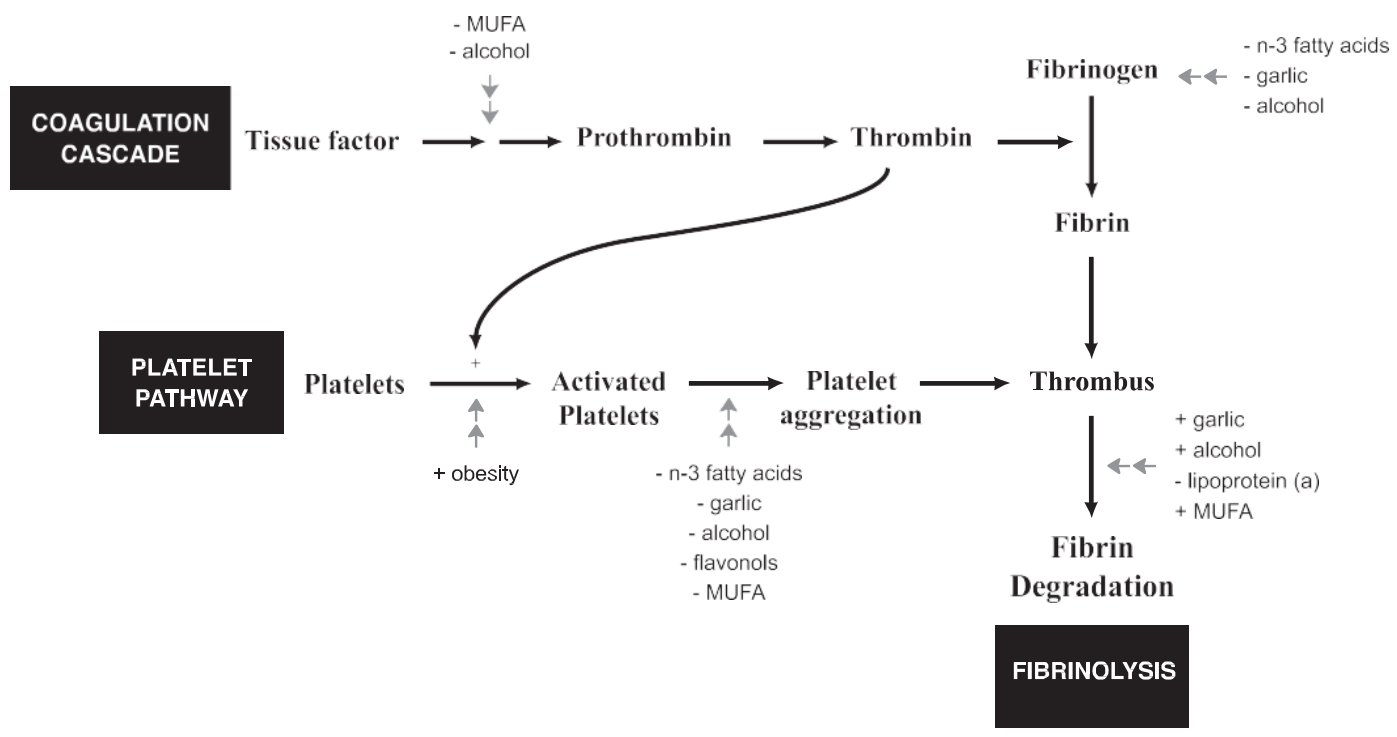

Fig. 2. Simplified pathway of hemostasis. Positive and negative dietary modifiers of components and pathways are shown with gray arrows. MUFA = monounsaturated fatty acids.

homology to plasminogen, which is largely responsible for the breakdown of fibrin clots. Plasminogen activation is blocked by LPA binding to fibrin and thus fibrinolysis is slowed [39]. The concentration of LPA is quite variable and is inversely correlated with the size of the apolipoprotein (a), which is under genetic control and hence the plasma concentration of LPA is not strongly affected by most dietary and environmental factors. There are several notable exceptions. Trans isomers of the monounsaturated fatty acid oleic acid may increase LPA substantially [40]. Fish oils have given variable effects generally in the protective direction [41].

Several classes of bioactive compounds found in plant foods are gaining increasing attention, in particular due to their antithrombotic effects. The flavonols, including quercetin, the catechins, and the epicatechins found in such diverse foods as apples, tea, cocoa, onions, and red wine, have been shown to lower platelet aggregation in vitro [42].

Compared to other energy sources such as saturated fatty acids and carbohydrates, monounsaturated fatty acids, such as those found in olive oil, have multiple protective effects on hemostasis. These include a lowering of platelet aggregation, lowering plasma levels of von Willebrand factor and factor VII and increasing fibrinolysis [43].

\section{Endothelial function}

In a sense, endothelial dysfunction is where all the risk factors meet. The initial prooxidant, inflammatory, dyslipidemic, and thrombotic effects meet in the deterioration of the vascular endothelium and the establishment of unstable plaques. For the purposes of this review, we will focus on a common functional test of endothelial function, flow-mediated vasodilation (FMV). Nitric oxide is the primary modulator of smooth muscle relaxation and vasodilation 
and induces FMV. Dietary elements that reduce nitric oxide synthesis reduce FMV and lead to deteriorating endothelial function.

A daily glass of red wine ameliorates the tendency of a high fat diet to decrease FMV [44]. A fruit and vegetable juice concentrate has a similar effect [45]. Other phytochemicals appear to increase FMV, including soy isoflavones [46], especially genistein [47].

Dietary fatty acids have varying effects on FMV. A 4-week replacement of saturated fatty acids by trans fatty acids saw a significant decrease of FMV as well as a significant decrease in HDL [48]. Conversely, both the n-3 fatty acids and the MUFAs lead to an increase in FMV [49,50]. Weight loss and exercise both improve FMV [51,52].

Homocysteine (HCY) is a byproduct of insufficient methyl group metabolism. In the 1960s McCully initially identified the role of homocysteinemia in the pathogenesis of atherosclerosis [53]. Three $\mathrm{B}$ vitamins, namely, $\mathrm{B}_{6}, \mathrm{~B}_{12}$, and especially folate, are instrumental in homocysteine metabolism (Fig. 3). HCY is detrimental to the endothelium, reducing the availability of nitric oxide, decreasing FMV, increasing intima-media thickening, and increasing arterial wall thickening [54,55]. HCY has been found to be higher in smokers and men and is positively associated with hard liquor intake and advancing age. Generally, the treatment of high HCY is straightforward: the administration of folate, vitamin $\mathrm{B}_{12}$, and vitamin $\mathrm{B}_{6}$, either in foods (particularly the leafy green vegetables) or as modest supplements. The $677 \mathrm{C} \mathrm{N}$ T genotype of methylenetetrahydrofolate reductase also causes high serum HCY levels and can be treated with high daily doses of folate [56]. As a risk factor for CHD in the United States, the effect of hyperhomocysteinemia may be declining because of the

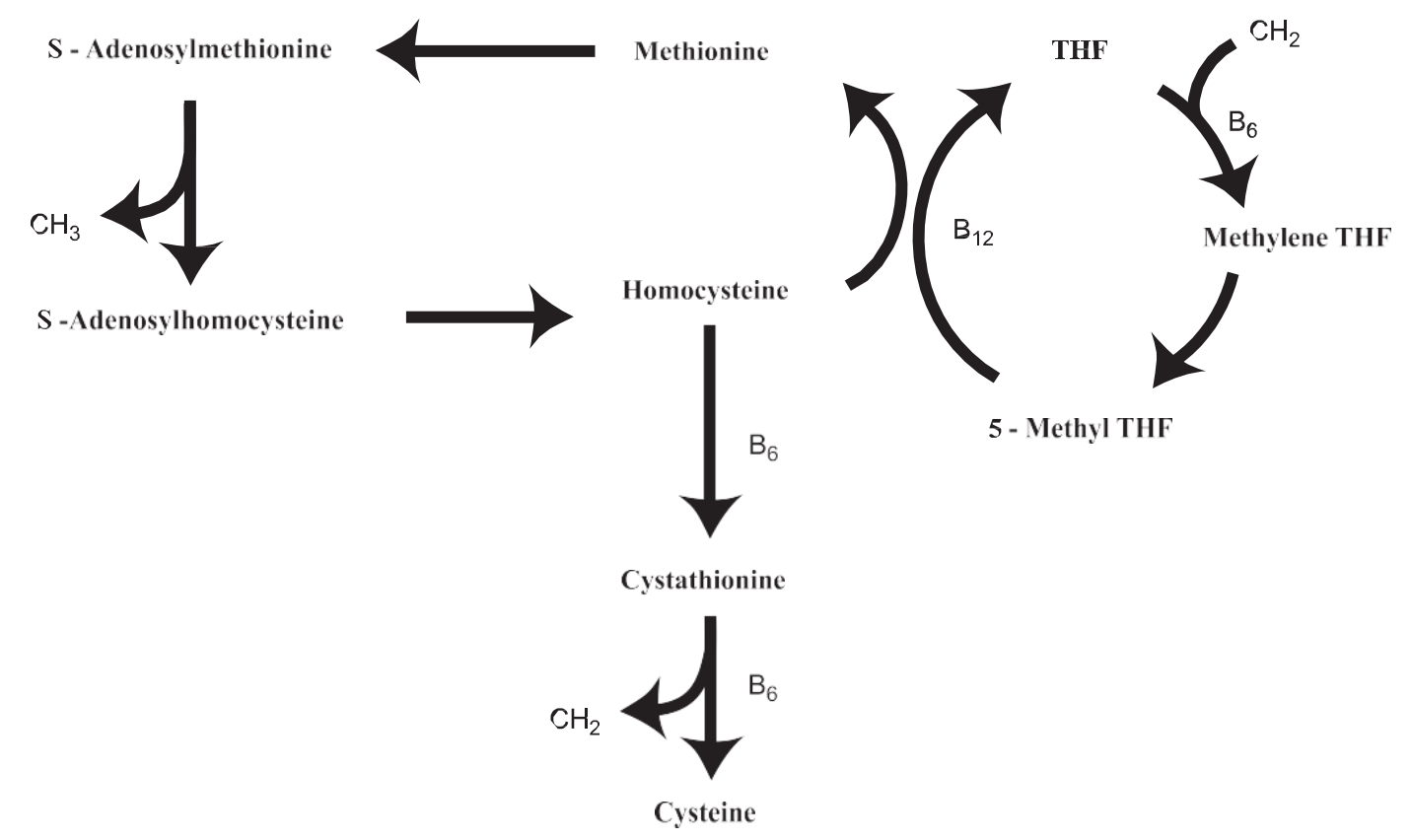

Fig. 3. Pathways of homocysteine and sulfur amino acid metabolism. B vitamins involved in enzymatic steps are indicated by arrows. $\mathrm{CH}_{2}=$ methylene; $\mathrm{CH}_{3}=$ methyl; $\mathrm{THF}=$ tetrahydrofolate . 
fortification of grains with folate since the mid 1990s. In one study the blood level of folate increased $38 \%$ since fortification [57].

\section{Conclusion}

Numerous observational and clinical studies have confirmed the effects of nutrients and other dietary elements on CHD that operate through pathways other than lowering LDL and triglyceride, raising HDL, or lowering blood pressure. Since dietary choices are based on foods and not specific nutrients, effective recommendations to prevent CHD need to be based on beneficial foods and dietary patterns. A constellation of healthy food choices for vascular health appears together in the various traditional diets of the Mediterranean countries. Based on the reviewed literature, the common beneficial components of these diets include olive oil with its MUFA, regular moderate wine consumption with meals, garlic use, copious fresh fruits and vegetables, low intake of red meat and saturated fat, increased fish consumption, and low glycemic index staple foods. The Lyon Diet Heart Study used this diet (with the addition of $a$-linolenic acid) to reduce recurring heart disease by $72 \%$ without lowering blood pressure, LDL cholesterol, and triglycerides, or raising HDL cholesterol.

In addition, nontraditional risk factors can be actively improved by more traditional recommendations, including maintaining a healthy body weight (BMI b 25), smoking cessation, and regular exercise. The regular consumption of fatty fish has clear cardioprotective effects. The addition of rather large amounts of trans fatty acids to the Western diet in recent decades is proving deleterious, and the pathways of the effects are being elucidated. HCY and its effects on the vascular endothelium can be easily controlled through a diet rich in dark green leafy vegetables and possibly a supplement of B vitamins at the modest levels found in most multivitamin pills.

Determining the physiological mode of action of these dietary elements is difficult. In addition, identifying the active components of the foods we consume is also a continuing challenge, particularly when considering the phytochemicals in the beneficial fruits and vegetables. Although the mechanisms of action of these dietary components are still being explored and much is not yet known, recommendations should not be withheld in regard to known foods and dietary patterns that may drastically lower CHD risk.

\section{Acknowledgment}

Support was provided to the authors by their institutions, with no conflicts of interest. The authors thank Karen Hibbert for preparing the figures.

\section{References}

[1] Keys A. Seven countries: a multivariate analysis of death and coronary heart disease. Cambridge (MA)7 Harvard University Press; 1980.

[2] de Lorgeril M, Salen P, Martin J-L, Monjaud I, Delaye J, Mamelle N. Mediterranean diet, traditional risk factors, and the rate of cardiovascular complications after myocardial infarction: final report of the Lyon Diet Heart Study. Circulation 1999;99:779-85. 
[3] Barzi F, Woodward M, Marfisi R, Tavazzi L, Valagussa F, Marchioli R. Mediterranean diet and all-cause mortality after myocardial infarction: results from the GISSI-Prevenzione trial. Eur J Clin Nutr 2003;57: 604-11.

[4] Ross R, Glomset JA. Atherosclerosis and the arterial smooth muscle cell: proliferation of smooth muscle is a key event in the genesis of the lesions of atherosclerosis. Science 1973;180:1332-9.

[5] Danesh J, Wheeler JG, Hirschfield GM, Eda S, Eiriksdottir G, Rumley A, et al. C-reactive protein and other circulating markers of inflammation in the prediction of coronary heart disease. N Engl J Med 2004;350: 1387-97.

[6] Morris C, Carson S. Routine vitamin supplementation to prevent cardiovascular disease: a summary of the evidence for the U.S. Preventive Services Task Force. Ann Intern Med 2003;139:56-70.

[7] Haddad J. Antioxidant and prooxidant mechanisms in the regulation of redox(y)-sensitive transcript factors. Cell Signal 2002;14:879-97.

[8] Li D, Saldeen T, Mehta J. Gamma-tocopherol decreases ox-LDL-mediated activation of nuclear factorkappa B and apoptosis in human coronary artery endothelial cells. Biochem Biophys Res Commun 1999;27:157-61.

[9] Simopoulos A. Omega-3 fatty acids in inflammation and autoimmune diseases. J Am Coll Nutr 2002;21: 495-505.

[10] Robinson D, Urakaze M, Huang R, Taki H, Sugiyama E, Knoell C, et al. Dietary marine lipids suppress continuous expression of interleukin-1 beta gene transcription. Lipids 1996;31:S23 - 31.

[11] Mozaffarian D, Pischon T, Hankinson SE, Rifai N, Joshipura K, Willett WC, et al. Dietary intake of trans fatty acids and systemic inflammation in women. Am J Clin Nutr 2004;79:606-12.

[12] Ridker PM, Cushman M, Stampfer MJ, Tracy RP, Hennekens CH. Inflammation, aspirin, and the risk of cardiovascular disease in apparently healthy men. N Engl J Med 1997;336:973-6.

[13] Imhof A, Froehlich M, Brenner H, Boeing H, Pepys M, Koenig W. Effect of alcohol consumption on systemic markers of inflammation. Lancet 2001;357:763-7.

[14] Liu S, Manson J, Buring J, Stampfer M, Willett W, Ridker P. Relation between a diet with a high glycemic load and plasma concentrations of high-sensitivity C-reactive protein in middle-aged women. Am J Clin Nutr 2002;75:492-8.

[15] Abramson J, Vaccarino V. Relationship between physical activity and inflammation among apparently healthy middle-aged and older US adults. Arch Intern Med 2002;162:1286-92.

[16] Esposito K, Pontillo A, Di Palo C, Giugliano G, Masella M, Marfella R, et al. Effect of weight loss and lifestyle changes on vascular inflammatory markers in obese women: a randomized trial. JAMA 2003;289: 1799-804.

[17] Jenkins D, Kendall C, Marchie A, Faulkner D, Wong J, de Souza R, et al. Effects of a dietary portfolio of cholesterol-lowering foods vs lovastatin on serum lipids and C-reactive protein. JAMA 2003;290: 502-10.

[18] Marchioli R, Barzi F, Bomba E, Chieffo C, Di Gregorio D, Di Mascio R, et al. Early protection against sudden death by n-3 polyunsaturated fatty acids after myocardial infarction: time-course analysis of the results of the Gruppo Italiano per lo Studio della Sopravvivenza nell' Infarto Miocardico (GISSI)Prevenzione. Circulation 2002;105:1897-903.

[19] Albert C, Campos H, Stampfer M, Ridker P, Manson J, Willett W, et al. Blood levels of long-chain n-3 fatty acids and the risk of sudden death. N Engl J Med 2002;346:1113-8.

[20] Hu F, Bronner L, Willett W, Stampfer M, Rexrode K, Albert C, et al. Fish and omega-3 fatty acid intake and risk of coronary heart disease in women. JAMA 2002;287:1815-21.

[21] Lemaitre R, King I, Mozaffarian D, Kuller L, Tracy R, Siscovick D. n-3 Polyunsaturated fatty acids, fatal ischemic heart disease, and nonfatal myocardial infarction in older adults: the Cardiovascular Health Study. Am J Clin Nutr 2003;77:319-25.

[22] Demaison L, Moreau D. Dietary n-3 polyunsaturated fatty acids and coronary heart disease-related mortality: a possible mechanism of action. Cell Mol Life Sci 2002;59:463-77.

[23] Pepe S, McLennan P. Dietary fish oil confers direct antiarrhythmic properties on the myocardium of rats. J Nutr 1996;126:34-42. 
[24] Billman G, Kang J, Leaf A. Prevention of sudden cardiac death by dietary pure omega-3 polyunsaturated fatty acids in dogs. Circulation 1999;99:2452-7.

[25] Leaf A, Kang J, Xiao Y, Billman G. Clinical prevention of sudden cardiac death by n-3 polyunsaturated fatty acids and mechanism of prevention of arrhythmias by n-3 fish oils. Circulation 2003;107: 2646-52.

[26] Xiao Y, Kang J, Morgan J, Leaf A. Blocking effects of polyunsaturated fatty acids on Na+ channels of neonatal rat ventricular myocytes. Proc Natl Acad Sci USA 1995;92:11000-4.

[27] Danesh J, Collins R, Appleby P, Peto R. Association of fibrinogen, C-reactive protein, albumin, or leukocyte count with coronary heart disease: meta-analyses of prospective studies. JAMA 1998;279: 1477-82.

[28] Cushman M, Lemaitre R, Kuller L, Psaty B, Macy E, Sharrett A, et al. Fibrinolytic activation markers predict myocardial infarction in the elderly. The Cardiovascular Health Study. Arterioscler Thromb Vasc Biol 1999;19:493-8.

[29] Thompson S, Kienast J, Pyke S, Haverkate F, van de Loo J. Hemostatic factors and the risk of myocardial infarction or sudden death in patients with angina pectoris. European Concerted Action on Thrombosis and Disabilities Angina Pectoris Study Group. N Engl J Med 1995;332:635-41.

[30] Folsom A, Wu K, Rosamond W, Sharrett A, Chambless L. Prospective study of hemostatic factors and incidence of coronary heart disease: the Atherosclerosis Risk in Communities (ARIC) Study. Circulation 1997;96:1102-8.

[31] Banerjee S, Maulik S. Effect of garlic on cardiovascular disorders: a review. Nutr J 2002;1:4.

[32] Ackermann R, Mulrow C, Ramirez G, Gardner C, Morbidoni L, Lawrence V. Garlic shows promise for improving some cardiovascular risk factors. Arch Intern Med 2001;161:813-24.

[33] Lacoste L, Hung J, Lam J. Acute and delayed antithrombotic effects of alcohol in humans. Am J Cardiol 2001;87:82-5.

[34] Ridker P, Vaughan D, Stampfer M, Glynn R, Hennekens C. Association of moderate alcohol consumption and plasma concentration of endogenous tissue-type plasminogen activator. JAMA 1994;272:929-33.

[35] Elmer O, Goransson G, Zoucas E. Impairment of primary hemostasis and platelet function after alcohol ingestion in man. Haemostasis 1984;14:223-8.

[36] Gorinstein S, Zemser M, Lichman I, Berebi A, Kleipfish A, Libman I, et al. Moderate beer consumption and the blood coagulation in patients with coronary artery disease. J Intern Med 1997;241:47-51.

[37] Gorinstein S, Caspi A, Goshev I, Aksu S, Salnikow J, Scheler C, et al. Structural changes in plasma circulating fibrinogen after moderate beer consumption as determined by electrophoresis and spectroscopy. J Agric Food Chem 2003;51:822-7.

[38] Baer DJ, Judd JT, Clevidence BA, Tracy RP. Dietary fatty acids affect plasma markers of inflammation in healthy men fed controlled diets: a randomized crossover study. Am J Clin Nutr 2004;79:969-73.

[39] Marcovina S, Koschinsky M. Evaluation of lipoprotein(a) as a prothrombotic factor: progress from bench to bedside. Curr Opin Lipidol 2003;14:361-6.

[40] Mensink R, Zock P, Katan M, Hornstra G. Effect of dietary cis and trans fatty acids on serum lipoprotein[a] levels in humans. J Lipid Res 1992;33.

[41] Haglund O, Luostarinen R, Wallin R, Wibell L, Saldeen T. The effects of fish oil on triglycerides, choles terol, fibrinogen and malondialdehyde in humans supplemented with vitamin E. J Nutr 1991;121: 1659.

[42] Kris-Etherton P, Hecker K, Bonanome A, Coval S, Binkoski A, Hilpert K, et al. Bioactive compounds in foods: their role in the prevention of cardiovascular disease and cancer. Am J Med 2002;113:71S-8S.

[43] Perez-Jimenez F, Lopez-Miranda J, Mata P. Protective effect of dietary monounsaturated fat on arteriosclerosis: beyond cholesterol. Atherosclerosis 2002;163:385-98.

[44] Cuevas AM, Guasch V, Castillo O, Irribarra V, Mizon C, San Martin A, et al. A high-fat diet induces and red wine counteracts endothelial dysfunction in human volunteers. Lipids 2000;35:143-8.

[45] Plotnick G, Corretti M, Vogel R, Hesslink Jr R, Wise J. Effect of supplemental phytonutrients on impairment of the flow-mediated brachial artery vasoactivity after a single high-fat meal. J Am Coll Cardiol 2003;41:1744-9. 
[46] Steinberg F, Guthrie N, Villablanca A, Kumar K, Murray M. Soy protein with isoflavones has favorable effects on endothelial function that are independent of lipid and antioxidant effects in healthy postmenopausal women. Am J Clin Nutr 2003;78:123-30.

[47] Squadrito F, Altavilla D, Crisafulli A, Saitta A, Cucinotta D, Morabito N, et al. Effect of genistein on endothelial function in postmenopausal women: a randomized, double-blind, controlled study. Am J Med 2003;114:470-6.

[48] de Roos N, Bots M, Katan M. Replacement of dietary saturated fatty acids by trans fatty acids lowers serum HDL cholesterol and impairs endothelial function in healthy men and women. Arterioscler Thromb Vasc Biol 2001;21:1233-7.

[49] Fuentes F, Lopez-Miranda J, Sanchez E, Sanchez F, Paez J, Paz-Rojas E, et al. Mediterranean and low-fat diets improve endothelial function in hypercholesterolemic men. Ann Intern Med 2001;134:1115-9.

[50] Wolfram G. Dietary fatty acids and coronary heart disease. Eur J Med Res 2003;8:321-4.

[51] Hambrecht R, Wolf A, Gielen S, Linke A, Hofer J, Erbs S, et al. Effect of exercise on coronary endothelial function in patients with coronary artery disease. N Engl J Med 2000;342:454-60.

[52] Roberts C, Vaziri N, Barnard R. Effect of diet and exercise intervention on blood pressure, insulin, oxidative stress, and nitric oxide availability. Circulation 2002;106:2530-2.

[53] McCully KS. Vascular pathology of homocysteinemia: implications for the pathogenesis of arteriosclerosis. Am J Pathol 1969;56:111-28.

[54] Mangoni A, Jackson S. Homocysteine and cardiovascular disease: current evidence and future prospects. Am J Med 2002;112:556-65.

[55] De Bree A, Verschuren W, Kromhout D, Kluijtmans L, Blom H. Homocysteine determinants and the evidence to what extent homocysteine determines the risk of coronary heart disease. Pharmacol Rev 2002;54:599-618.

[56] Pullin C, Ashfield-Watt P, Burr M, Clark Z, Lewis M, Moat S, et al. Optimization of dietary folate or lowdose folic acid supplements lower homocysteine but do not enhance endothelial function in healthy adults, irrespective of the methylenetetrahydrofolate reductase (C677T) genotype. J Am Coll Cardiol 2001;38: 1799-805.

[57] Choumenkovitch S, Jacques P, Nadeau M, Wilson P, Rosenberg I, Selhub J. Folic acid fortification increases red blood cell folate concentrations in the Framingham study. J Nutr 2001;131:3277-80. 